\title{
EXPERIMENTAL INVESTIGATION ON PERFORMANCE AND EMISSION CHARACTERISTICS OF DUAL FUEL SPLIT INJECTION OF ETHANOL AND DIESEL IN CI ENGINE
}

\author{
Terrin Babu P. ${ }^{1}$, Banugopan V.N. ${ }^{2}$, Srivathsan P.R. ${ }^{3}$, Prabhakar S. ${ }^{4}$, Annamalai K. ${ }^{5}$ \\ ${ }^{1,3}$ Department Of Manufacturing Engineering, CEG campus, Anna University Chennai-25, INDIA \\ 2,4,5 Department Of Automobile Engineering, MIT campus, Anna University-Chennai-44, INDIA \\ Email : 1 terrinbabu@gmail.com
}

\section{Abstract}

\begin{abstract}
The increasingly strict restrictions being place on diesel engine emissions have the interest in alternative combustion concept. The dual fuel engine exhibits much better emission characteristics than a diesel engine whilst having similar efficiency. The dual fuel engine is investigated for their potential to achieve near zero nitrogen oxide (NOx) and soot-particle emissions. In both SI and diesel engines, the fuel must burn hot to ensure that the flame spreads rapidly through the combustion chamber before a new "charge" enters. In a dual fuel split injection engine, there is no need for a quickly spreading flame because combustion occurs throughout the combustion chamber. As a result, combustion temperatures can be lower, so emissions of nitrogen pollutants are negligible. The fuel is spread in low concentrations throughout the cylinder, so the soot emissions from fuel-rich regions in diesels are not present. As the method for reducing exhaust emissions from diesel engines, a homogenous charge diesel combustion technique is used where by a portion of fuel is supplied into the intake port to form homogenous pre mixture then the mixture is fed into the cylinder port before ignition of the diesel fuel, which is injected directly into the cylinder. The homogeneous pre mixture is prepared with the help of electronic fuel injection.
\end{abstract}

Keywords- ethanol and diesel, split injection

\section{INTRODUCTION}

Dual fuel engine is a form of internal combustion in which well mixed fuel and oxidizer (typically air) are compressed to the point of auto-ignition. As in other forms of combustion, this exothermic reaction releases chemical energy into a sensible form that can be translated by an engine into work and heat Contents[3],[6]. Dual fuel engine is an alternative piston-engine combustion process that can provide efficiencies as high as compression-ignition direct-injection (CIDI) engines producing ultra low oxides of nitrogen (NOx) and particulate matter (PM) emissions. Dual fuel engines operate on the principle of having a dilute, premixed charge that reacts and burns volumetrically throughout the cylinder rather than in a flame front as it is compressed by the piston[3].

\section{START OF COMBUSTION IN THREE TYPES OF ENGINES}

In the fig 1.,(a)spark-ignition engine (left), combustion begins when a mixture of fuel and air is ignited by the spark plug. (b) In a diesel engine (center), combustion begins when fuel is injected into hot, highly compressed air.

(c) In a dual fuel engine (right), well-mixed fuel and air is compressed until combustion occurs at multiple points throughout the combustion chamber[3].

\section{PRINCIPLE OF OPERATION OF DUAL FUEL ENGINES}

Dual fuel engines operate on the principle of having a dilute, premised charge that reacts and burns volumetrically throughout the cylinder rather than in a flame front as it is compressed by the piston.

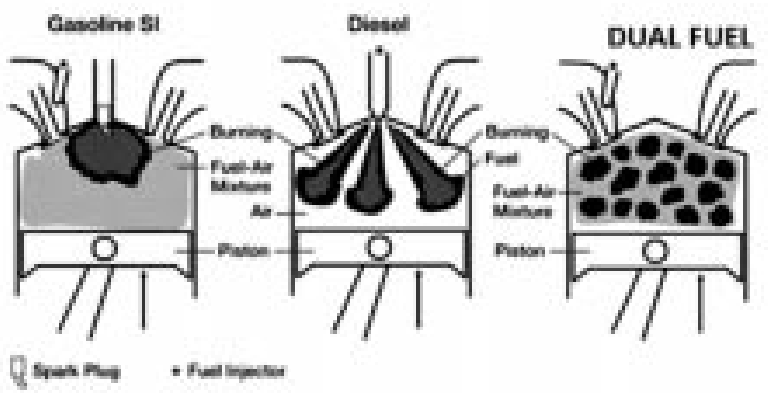

Fig 1. start of combustion in three type of engines 
In some regards, dual fuel incorporates the best features of both spark ignition (SI) and compression ignition (Cl). As in an SI engine, the charge is well mixed, which minimizes particulate emissions and as in a CIDI engine,

Dual fuel engine allows combustion to occur at much lower temperatures, dramatically reducing engine-out emissions of NOX.

Most engines employing this type of engine have dual mode combustion systems in which traditional SI or $\mathrm{Cl}$ combustion is used for operating conditions. Typically the engine is cold started as an SI or CIDI engine, then switched to dual mode for idle and mid-load operation to obtain the benefits of typical automotive driving cycles. For high load operation, the engine would again be switched to SI or CIDI operation[3].

\section{IV.CHALLENGES IDENTIFIED IN DUAL FUEL ENGINES}

The main areas still requiring $R \& D$ to overcome the challenges [1] identified include

- Ignition timing control: research is needed to develop control methods for dual fuel engines in order to overcome the challenge of maintaining proper ignition timing as load and speed are varied.

- Combustion rate control for high-load engine operation: Research is needed to develop methods that slow the heat release rate in dual fuel engines at high-load operation to prevent excessive noise or engine damage.

- Engine cold-start: R \& D is needed to develop an advanced cold start concept to overcome the challenge of achieving ignition at low temperatures without compromising warm engine performance.

- Development of emission control systems: R \&D is needed to develop emission control systems and control strategies to overcome the challenge of excessive $\mathrm{HC}$ and $\mathrm{CO}$ emissions, particularly at low loads.

- Achieving satisfactory engine transient operation: $R$ $\& D$ is needed to develop a fast-response control system to overcome the challenge of maintaining proper ignition timing during rapid variations in engine speed and load.

- Development of engine control strategies and systems: Research is needed to develop a methodology for feedback and closed-loop control of the fuel and air systems to keep the combustion optimized over the load speed range in a production vehicle. New sensors may be needed to achieve this level of control.

\section{HOMOGENOUSLY CHARGED DIESEL}

In conventional diesel injection diesel engines, although it is a lean combustion in average because the fuel is sprayed into the cylinder, spatial distribution of air fuel ratios in the combustion chamber varies widely from rich to lean. NOx is formed at stoichiometric zone between rich and lean regions and smoke is formed at diffusion combustion region.

In order to reduce such harmful substance drastically, some researches were attempted such that the pre-mixture was formed at the starting ignition and lean-burn is performed in overall combustion chamber. This is called as dedicated dual fuel engine concept.

\section{MANIFOLD FUEL INJECTION}

- The premixed fuel used is ethanol.

- Ethanol is injected at the inlet air port near the inlet valve. Injector is placed at an angle of 30 degrees with respect to horizontal plane[1]. Ethanol is injected at a low pressure of 3 bar by the solenoid operated fuel injector into the intake manifold at TDC.

- The higher latent heat of vaporization of ethanol with its fine volatility gives better mixing with the air and homogenous mixture is prepared. The amount of fuel injection is based on the premixed ratio. Varying the pulse width given to the solenoid operated fuel injector by an electronic controller which controls the fuel injection quantity. (fig 2)

\section{DEFINITION OF PREMIXED RATIO}

The premixed ration $r_{p}$ is defined as the ration of energy of pre mixed fuel $Q_{p}$ to the total energy $Q_{t}$, which can be expressed as

$$
\begin{aligned}
& r_{p}=Q_{p} / Q_{t} \\
& Q_{t}=m_{p} h_{u p}+m_{d} h_{u d},
\end{aligned}
$$


$Q_{p}=m_{p} h_{u p}$

Where $m_{p}=$ premixed fuel mass

$m_{d}=$ Diesel fuel mass

$h_{u p}=$ Lower heating value of premixed fuel

$h_{u d}=$ Lower heating value of Diesel fuel

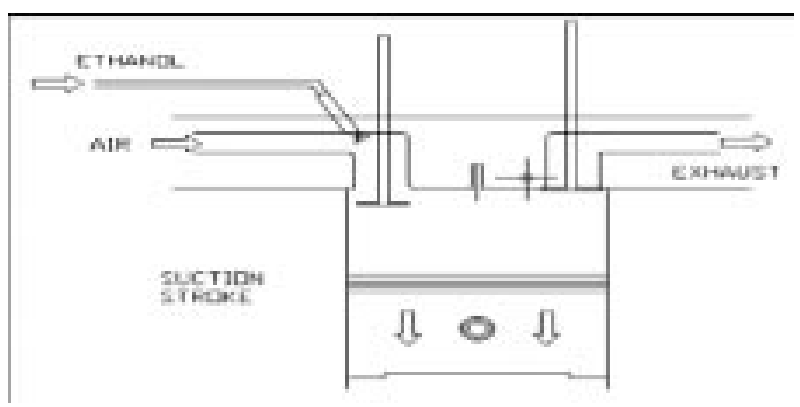

Fig 2. Manifold Fuel Injector Location

\section{USAGE OF ETHANOL AS A PREMIXED FUEL}

Ethanol is a bio mass -based renewable fuel having cleaner burning characteristics and can reduce smoke emission from diesel engines. Ethanol can be manufactured by fermentation of grains and sugar cane. Ethanol can be used in diesel engines by different techniques; namely ethanol-diesel blending, ethanol-diesel emulsion, ethanol fumigation, dual injection with diesel, providing spark ignition and by addition of ignition improvers to the ethanol[2]. Ethanol has been chosen as a primary fuel for $\mathrm{HCCl}$ engine because its high octane number. so there might not be knocking problem when engine operates on full load condition in $\mathrm{HCCl}$ mode of combustion. Ethanol has high latent heat of vaporization, which can result in cooler intake process, which can increase the volumetric efficiency of the engine; ethanol has a high volatility so it will vaporize easily to form a homogenous mixture with air. Ethanol has stability in $\mathrm{HCCl}$ combustion mode on operating at wider loads and speeds[2]. The properties of ethanol are given in table 1.

\section{PREMIXED FUEL QUANTITY}

The performance test on the diesel engine was conducted and the fuel consumptions were calculated at different loads[4]. Based on the fuel consumption for diesel, the fuel consumed
TABLE 1 Properites of ethanol

\begin{tabular}{|l|c|}
\hline Chemical structure & $\mathrm{CH}_{3}-\mathrm{CH}_{2}-\mathrm{OH}$ \\
\hline Lower calorific value(MJ/kg) & 26.952 \\
\hline Density at $20^{\circ} \mathrm{C}\left(\mathrm{kg} / \mathrm{m}^{3}\right)$ & 789 \\
\hline Auto ignition temperature $\left({ }^{\circ} \mathrm{C}\right)$ & 422 \\
\hline Flash point $\left({ }^{\circ} \mathrm{C}\right)$ & 13 \\
\hline Latent heat of vaporization $\mathrm{KJ} / \mathrm{kg}$ & 846 \\
\hline Cetane no & 8 \\
\hline Octane no & 108 \\
\hline Stoichiometric air/ fuel ratio & 9.0 \\
\hline Boiling point ( $\left.{ }^{\circ} \mathrm{C}\right)$ & 78.4 \\
\hline Ignition limit Air / Fuel Ratio & $3.57-17$ \\
\hline
\end{tabular}

per stroke was calculated and then the premixed fuel quantity at different premixed ratio up to $20 \%$ was calculated based on the energy equivalence as discussed in the section above. To measure the ethanol fuel injected at different injection duration and different injection pressure, preliminary tests were conducted by placing fuel injector outside the intake manifold and collecting the fuel injected in a graduated test tube.

\section{PRE MIXED FUEL INJECTION SYSTEM}

The electronic fuel injection system for pre-mixed fuel consists of electronic fuel injector, rotary fuel pump, fuel tank, pump driver, filter, ECU and crank angle position sensor[1]. The details of the various components are given in detail. The fuel pump supplies the fuel from the fuel tank to the fuel injector at high pressure. The fuel injector(fig 3 ) will be operated by getting the signal from the ECU[5],[7]. The crank angle position sensor is used to determine the position of the crank shaft with the help of this data the ECU will give control signal to operate the fuel injector at the correct position for every cycle. The length of the pulse determines the quantity of the fuel to be delivered[4],[5]. 


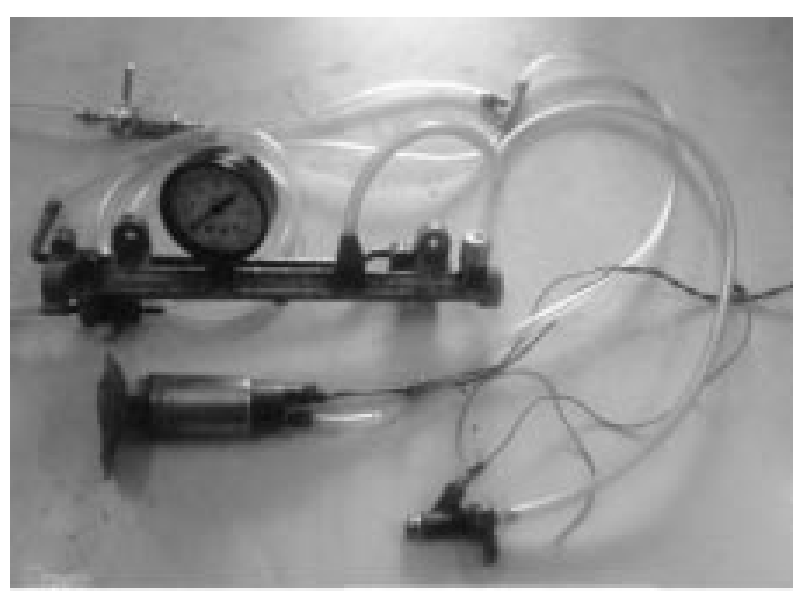

Fig 3. Premixed fuel supply circuit

\section{A. ELECTRONIC FUEL INJECTOR}

An injector used in the throttle body injection system of Daewoo motors is to be used for the investigation. The rating of the fuel injector is $12 \mathrm{~V}$, $1 A[1]$. The fuel injector shown in figure is connected with common rail assembly to reduce the pressure coming out from the pump to injector and giving the required pressure nearly 3 bar[6].

\section{B. FUEL FEED PUMP}

The rotary fuel pump used in the Hyundai santro car as shown in the figure will be used for the research. Its delivery pressure is about 7 bar with a pressure regulator a constant pressure of 3 bar is achieved.

\section{COMMON RAIL SYSTEM}

The common rail system used in the Hyundai santro car is used consisting of pressure regulator. Pressure gauge is attached to the common rail to monitor the pressure maintained inside the common rail system. The pressure regulator is used to maintain the pressure of 3 bar inside the common rail excess fuel is returned back to the fuel tank.

\section{EXPERIMENTAL SET UP}

The test engine is a single cylinder, direct injection, four-stroke cycle diesel engine of $662 \mathrm{~cm}^{3}$ of displacement. The intake port system of diesel engine was modifies for ethanol fuel injection. The premixed fuel injection system is composed of solenoid operated type fuel injector and injection controller [7],[8]. The specifications and dimension of the engine are listed in appendix. An infrared sensor was used to sense the position of the crank shaft and gives senses to the electronic control unit. The start of the injection and injection duration of the injector were controlled by using the ECU[1],[6],[7],[8]. An electric pump is used for ethanol pressurizing, which operates at 7 bar. The ECU gives energizing pulse to the solenoid operated injector and controls the injection timing and injection duration. The premixed fuel quantity for different premixed ratio was calculated on the energy basis. The premixed ratio is defined as the ratio of the energy of premixed fuel to the total energy from diesel and premixed fuel. The total fuel consumption for diesel fuel was found at all loads, based on which the premised fuel quantity at different premixed ratio was calculated.

The premixed fuel quantity for different premixed ratio was obtained by adjusting injection duration controller in ECU and fuel injection pressure in the range of 0.5 to 2.5 bar[5]. Ethanol is injected at TDC during intake stroke and diesel is injected at $26^{\circ} \mathrm{BTDC}$ at end of compression stroke. The premixed fuel quantity increases on increasing premixed ratios and diesel injected directly into combustion chamber was reduced. $\mathrm{NOx}, \mathrm{UBHC}, \mathrm{CO}, \mathrm{CO}_{2}$ emissions were measured using a five gas analyzer (fig 8). The test engine was maintained at a speed of 1500 RPM through out the experiments (fig 5,6).

\section{CRANKSHAFT POSITION SENSOR}

The crankshaft position sensor (fig 4) is designed to record the rate at which the crankshaft is spinning. The optical sensor consists of a. Led transmitter and receiver and the disc attached to the cam shaft. When the engine reaches TDC during the suction stroke the path between the led transmitter and receiver is cut by the small projection in the disc attached to the cam shaft disc. This signal is given to ECU which gives the necessary signal to the fuel injector for injecting the fuel at the required position[1],[3].

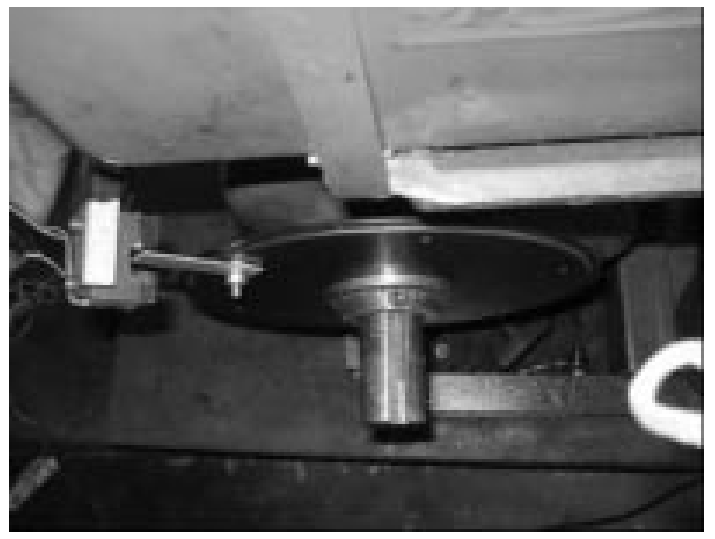

Fig 4. Crankshaft position sensor 


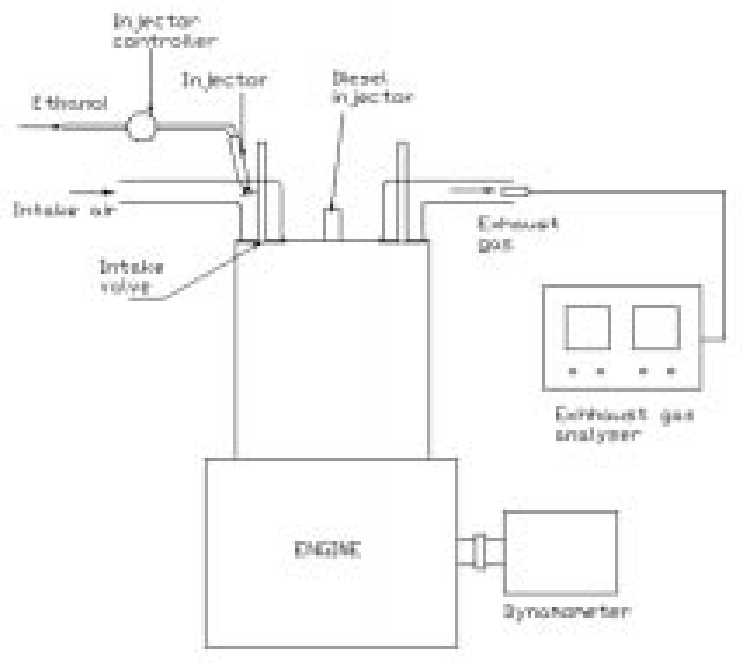

Fig 5 Experimental set up

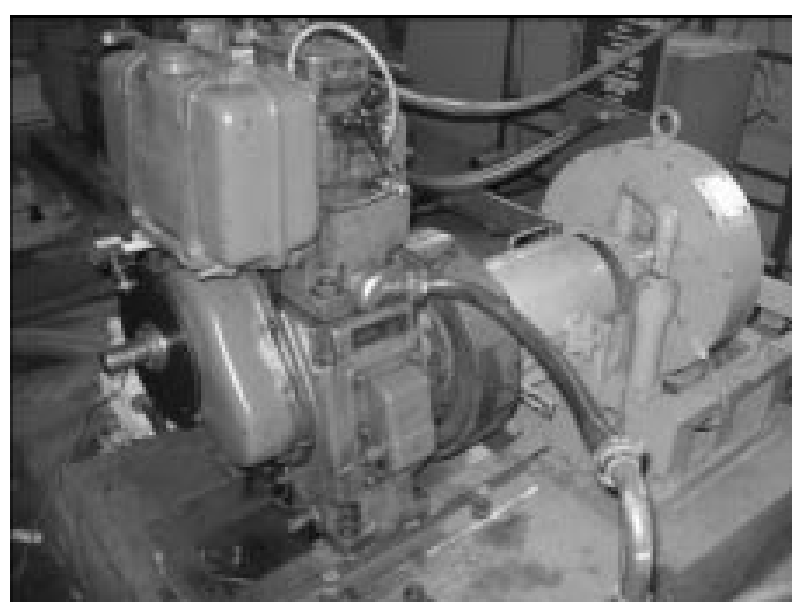

Fig 6. Single cylinder kirloskar taf-1

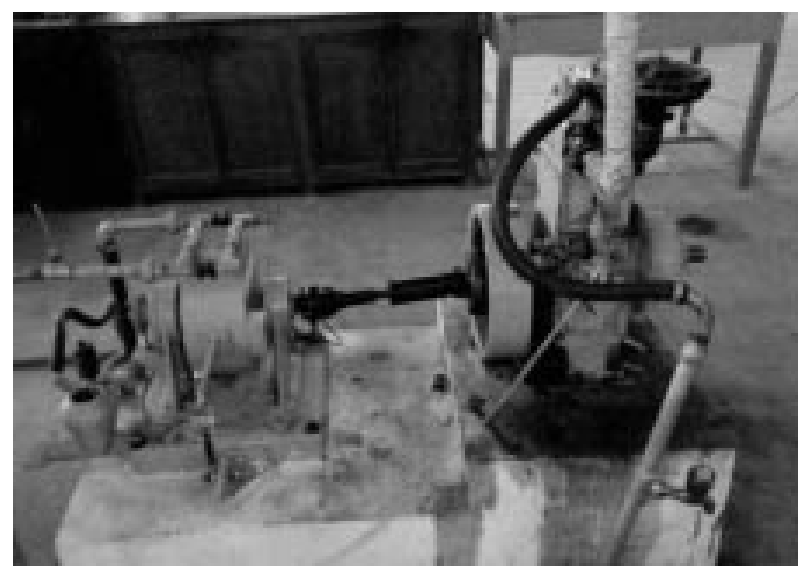

Fig 7. Dynamometer

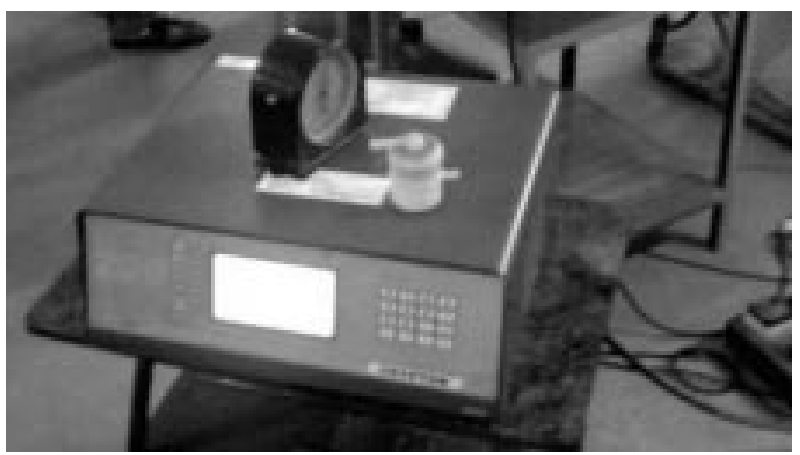

Fig 8. AVL Analyser

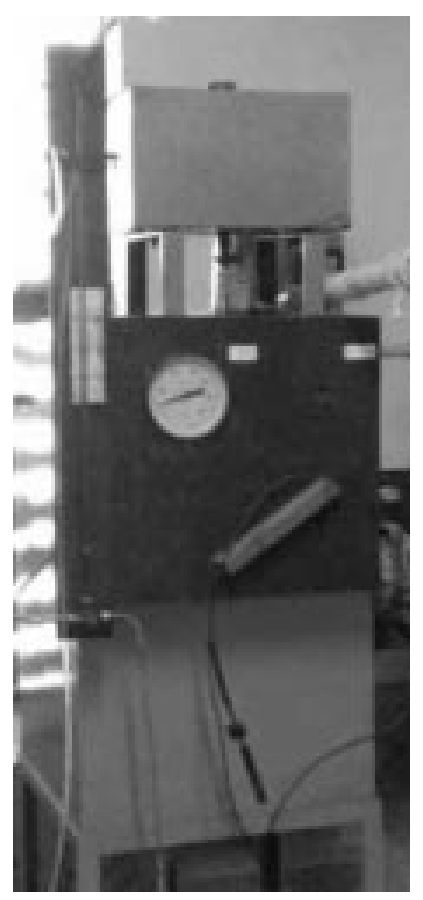

Fig 9. Fuel Supply

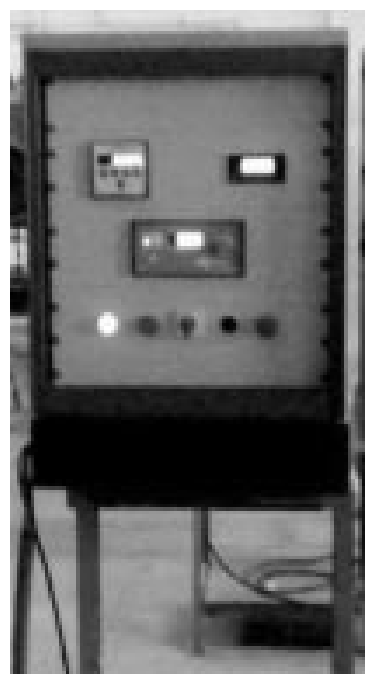

Fig 10. Voltage and Current Variation 


\section{RESULTS AND DISCUSSIONS}

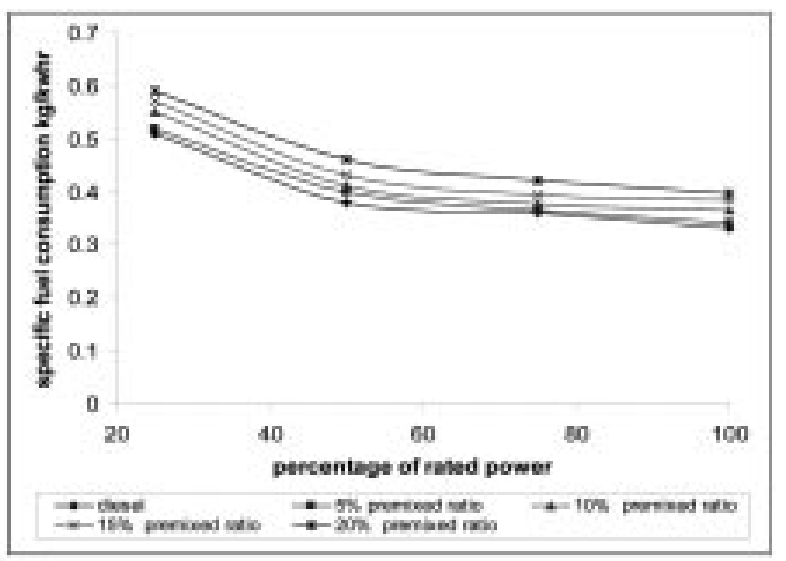

Fig 4. Comparison of Specific Fuel Consumption

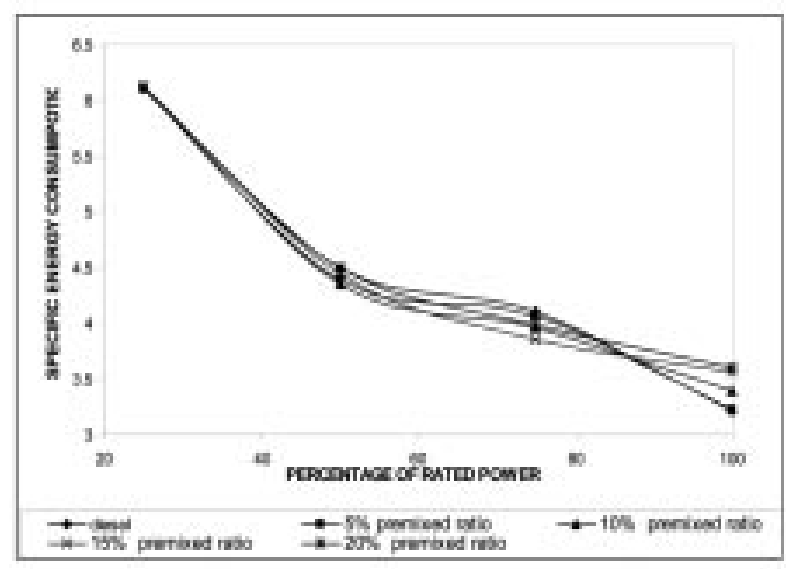

Fig 5. Comparison of Specific Energy Consumption

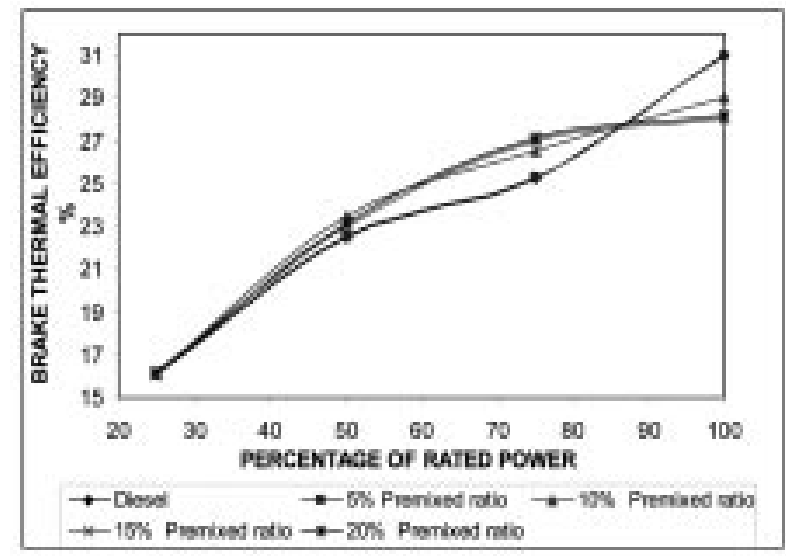

Fig 6. Comparison of Brake Thermal Efficiency

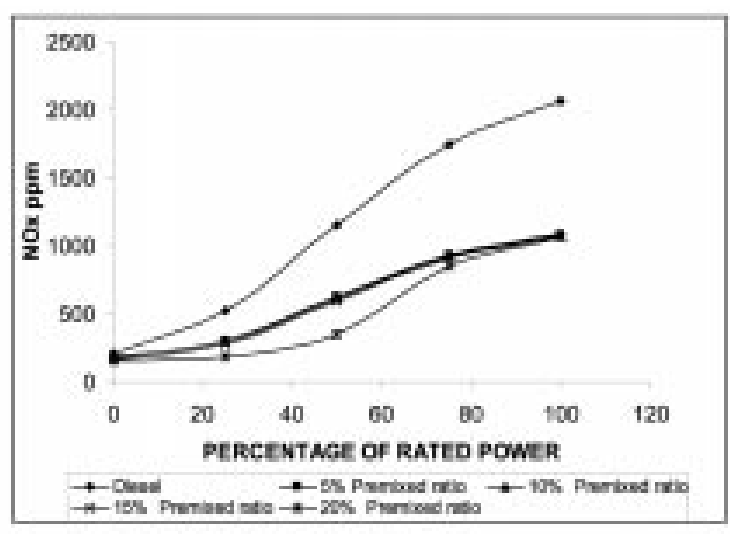

Fig 7. Effect of Premixed Fuel Ratio on Nox Emission

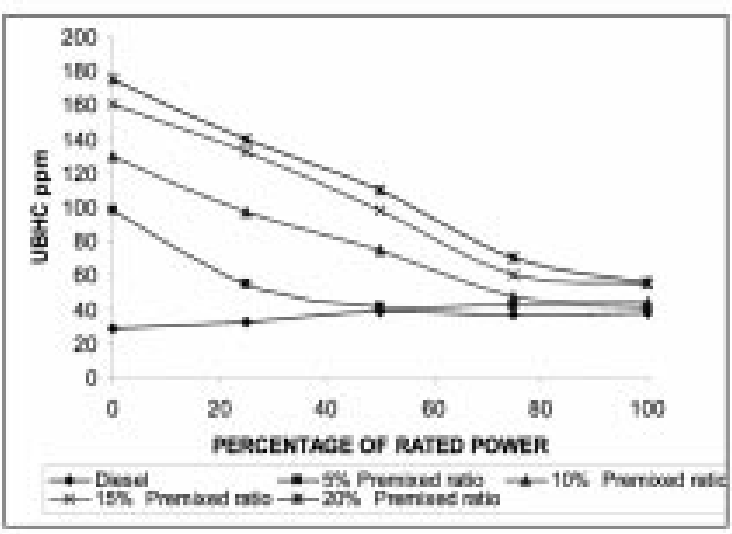

Fig 8. Effect of Premixed Fuel Ratio on Unburned Hydro Carbon emission

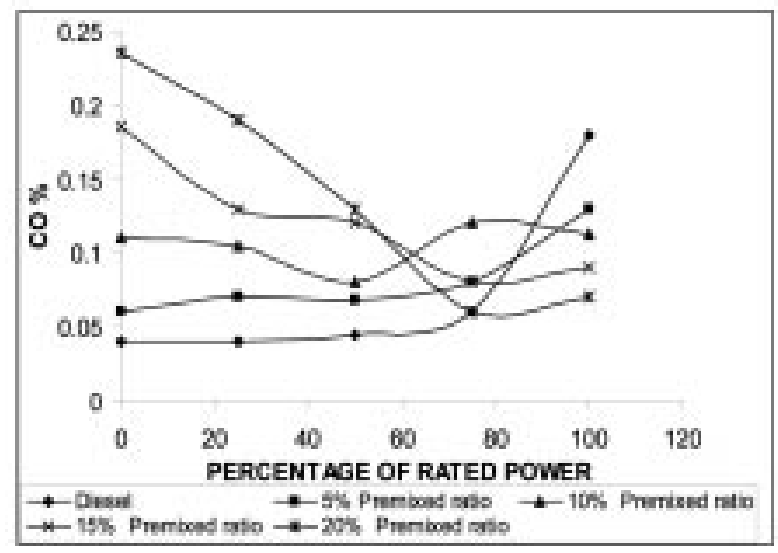

Fig 9. Effect of Premixed Ratio on Carbon Monoxide Emission 


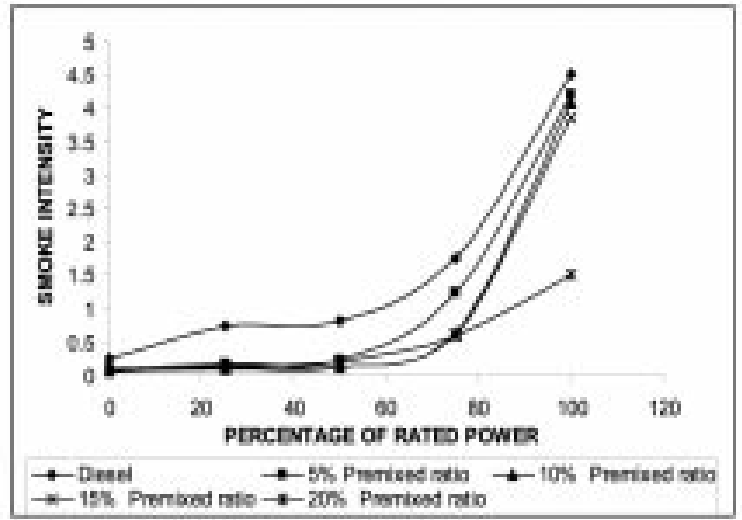

Fig 10. Effect of Premixed Ratio on Smoke Intensity

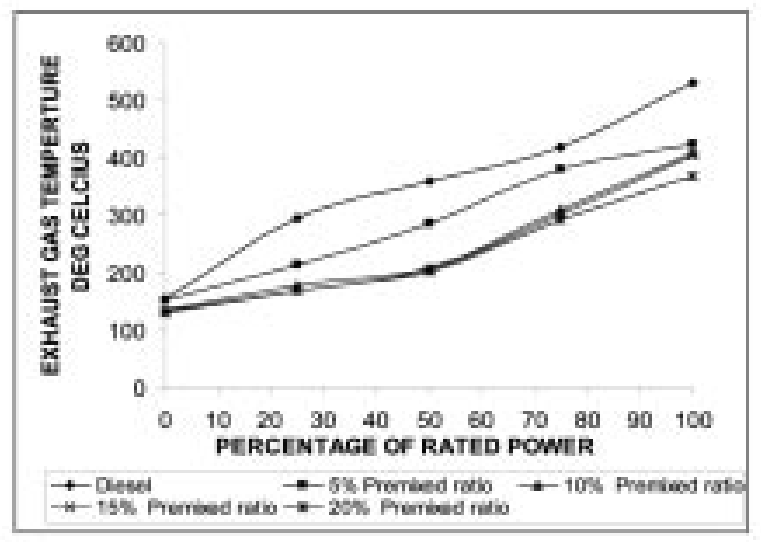

Fig 11. Effect of Premixed Ratio on Exhaust Gas Temperature

TABLE 2. Engine specifications

\begin{tabular}{|c|c|}
\hline Engine make & Kirloskar taf-1 \\
\hline Number of cylinders & One \\
\hline Type of cooling & Air cooled \\
\hline Ignition & Compression ignition \\
\hline Bore & $87.5 \mathrm{~mm}$ \\
\hline Stroke & $110 \mathrm{~mm}$ \\
\hline Compression ratio & $17.5: 1$ \\
\hline Speed & $1500 \mathrm{rpm}$ \\
\hline Rated power & $4.4 \mathrm{kw}$ \\
\hline
\end{tabular}

TABLE 3. Valve timing

\begin{tabular}{|c|c|}
\hline Inlet valve opening & $4.5^{\circ} \mathrm{bTDC}$ \\
\hline Inlet valve closing & $35.5^{\circ} \mathrm{aBDC}$ \\
\hline Exhaust valve opening & $35.5^{\circ} \mathrm{bBDC}$ \\
\hline Exhaust vale closing & $4.5^{\circ} \mathrm{aTDC}$ \\
\hline Start of Diesel Injection & $23^{\circ} \mathrm{bTDC}$ \\
\hline Start of Ethanol Injection & $4.5 \mathrm{bTDC}$ \\
\hline
\end{tabular}

\section{CONCLUSION}

From the experimental results obtained from diesel engine working in dual engine mode the following conclusions were drawn.

1. With the increase in premixed ratio of ethanol with diesel, there was a significant decrease in the NOx. About 49\% reduction in NOx emission was achieved. The exhaust gas temperature decreased with the increase in premixed fuel ratio (fig 7).

2. The specific energy consumption was high only at the full load condition on using $15 \%$ and $20 \%$ premixed ratio of ethanol. At part load condition, the specific energy consumption was less(fig 5).

3. The smoke reduction was significant both at $75 \%$ and full load condition with increase in the premixed ratio using $20 \%$ premixed ratio, there was $64 \%$ reduction in smoke intensity when compared with smoke intensity obtained from the diesel at full load(fig 10).

4. With the increase in premixed ratio, the carbon monoxide emissions increased at low and part load conditions. About $61 \%$ reduction in carbon monoxide was achieved when compared to the diesel fueling at full load(fig 9).

5. The drawback of dual fuel combustion technique was the increase in unburned carbon emissions. UBHC increases in dual fuel mode as premixed ratio increases when compared to the diesel fueling, which is considerably high at no load (fig 8). 
Based on the combustion and emission characteristics, the $20 \%$ premixed ratio was chosen as optimal premixed ratio of ethanol with diesel, as there was significant reduction in NOx and smoke and increase in brake thermal efficiency at part loads.

\section{ACKNOWLEDGMENTS}

The authors gratefully acknowledge the support given to this research by Department of Automobile Engineering (Madras Institute of Technology campus, Anna University, Chennai-44) and Department of manufacturing Engineering (College of Engineering guindy, Anna university, Chennai-25).

\section{REFERENCES}

1. Matsuo Odaka And Hisakazu Suzuki-"search for optimizing control method of homogenous charge diesel combustion"-SAE JOURNAL (1999-01-0184)
2. Per Risgerg- "Auto-ignition quality of diesel like fuels in $\mathrm{HCCl}$ engines" SAE journal (2005-01-2127)

3. Hunter Mack J. - "The effect of the di-tertiary butyl peroxide (DTBP) additive on $\mathrm{HCCl}$ combustion of fuel blends of ethanol and diethyl ether" SAE journal (2005-01-2135)

4. Hisashi Akagawa -"Approach to solve problems of the premixed lean diesel combustion" - SAE Journal (1999-01-0183)

5. Ra Y. "The use of variable geometry sprays with low pressure injection for optimization of diesel $\mathrm{HCCl}$ engine combustion"- SAE journal (2005-01-0148)

6. Weedig Gong - "Using pilot diesel injection in a natural gas fueled $\mathrm{HCCl}$ engine" -SAE journal (2002-01-2866)

7. Ajay V Deshmukh (2005) "microcontrollers [theory and application]" Tata mcgraw-hill pub.comp.Itd., New Delhi

8. Bosch (2004) "automotive electrics automotive electronics" Bentley publishers, U.S.A 